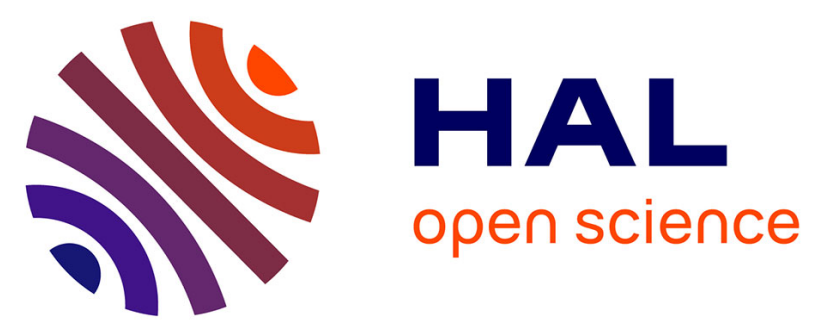

\title{
Functionnalized Surface Acoustic Wave Sensors for the Detection of Hazardous Gases
}

\author{
Claude P. Gros, Meddy Vanotti, Christophe Theron, Valentin Quesneau, \\ Valérie Soumann, Mario Naitana, Stéphane Brandès, Nicolas Desbois, Claude \\ Gros, Thu-Hoa Tran-Thi, et al.
}

\section{To cite this version:}

Claude P. Gros, Meddy Vanotti, Christophe Theron, Valentin Quesneau, Valérie Soumann, et al.. Functionnalized Surface Acoustic Wave Sensors for the Detection of Hazardous Gases. 2018 IEEE SENSORS, Oct 2018, New Delhi, India. pp.1-4, 10.1109/ICSENS.2018.8589669 cea-02367537

\section{HAL Id: cea-02367537 https://hal-cea.archives-ouvertes.fr/cea-02367537}

Submitted on 18 Nov 2019

HAL is a multi-disciplinary open access archive for the deposit and dissemination of scientific research documents, whether they are published or not. The documents may come from teaching and research institutions in France or abroad, or from public or private research centers.
L'archive ouverte pluridisciplinaire HAL, est destinée au dépôt et à la diffusion de documents scientifiques de niveau recherche, publiés ou non, émanant des établissements d'enseignement et de recherche français ou étrangers, des laboratoires publics ou privés. 


\section{Functionnalized Surface Acoustic Wave Sensors for the Detection of Hazardous Gases}

\author{
Meddy Vanotti \\ Time and frequency Department, FEMTO-ST Institute \\ 26 ch. de l'Epitaphe 25030 Besançon, France \\ Email: meddy.vanotti@femto-st.fr
}

\author{
Christophe Théron \\ NIMBE, UMR 3685, CEA, CNRS, \\ Université Paris-Saclay, CEA-Saclay \\ 91191 Gif-sur-Yvette, France \\ Email: theronchris@gmail.com
}

\section{Valentin Quesneau \\ ICMUB, UMR CNRS 6302}

9 avenue Alain Savary BP 4787021078 Dijon Cedex, France

Email: valentin.quesneau@u-bourgogne.fr

Mario Naitana

ICMUB, UMR CNRS 6302

9 avenue Alain Savary BP 4787021078 Dijon Cedex, France 9 avenue
Email: mario.naitana@u-bourgogne.fr

Nicolas Desbois

ICMUB, UMR CNRS 6302

\author{
Valérie Soumann \\ Time and frequency Department, FEMTO-ST Institute \\ 26 ch. de l'Epitaphe 25030 Besançon, France \\ Email: valerie.soumann@femto-st.fr
}

\section{Stéphane Brandès \\ ICMUB, UMR CNRS 6302}

Alain Savary BP 4787021078 Dijon Cedex, France

Email: stephane.brandes@u-bourgogne.fr

\author{
Claude P. Gros \\ ICMUB, UMR CNRS 6302
}

9 avenue Alain Savary BP 4787021078 Dijon Cedex, France 9 avenue Alain Savary BP 4787021078 Dijon Cedex, France Email: nicolas.desbois@u-bourgogne.fr

Email: claude.gros@u-bourgogne.fr

Thu-Hoa Tran-Thi

NIMBE, UMR 3685, CEA, CNRS,

Université Paris-Saclay, CEA-Saclay

91191 Gif-sur-Yvette, France

Email: thu-hoa.tran-thi@cea.fr
Virginie Blondeau-Patissier

Time and frequency Department, FEMTO-ST Institute

26 ch. de l'Epitaphe 25030 Besançon, France

Email: virginie.blondeau@femto-st.fr

\begin{abstract}
In this work, we show the capabilities of Surface Acoustic Wave (SAW) devices to probe the properties of gas sensitive materials for the manufacturing of hazardous gas sensors. The great capabilities of cobalt corroles for the trapping of carbon monoxide (CO) were exploited to produce selective sensors. These corroles were deposited on SAW delay lines surfaces and then exposed to carbon monoxide (CO) in standard conditions. Concentrations of a few hundreds of ppb were measured emphasizing the interest of such sensors for the detection of $\mathrm{CO}$. Another type of sensitive layers exhibiting specific porosity adapted to the trapping of formaldehyde $\left(\mathrm{CH}_{2} \mathrm{O}\right)$ were deposited on similar delay lines. A detection threshold of $140 \mathrm{ppb}$ was shown. These encouraging results pave the way for the development of a functionalized SAW sensors network for multi-gas detection in indoor air.
\end{abstract}

\section{INTRODUCTION}

During the last two decades, the potential impact of indoor air quality on human health has stimulated an interest in hazardous compounds survey such as formaldehyde $\left(\mathrm{CH}_{2} \mathrm{O}\right)[1]$ and carbon monoxide (CO) [2].Formaldehyde being a carcinogenic, the World Health Organization (WHO) recommends exposure limit as low as $80 \mathrm{ppb}$ of formaldehyde during 30 minutes [3]. The French Institute for Health Surveillance (InVS) reports that accidental domestic poisoning by the CO affects about 1000 households in France each year [4], and are responsible for about 100 deaths. The detection of these two compounds has consequently become a need. To address these needs, we here report results on the capability of functionalized Surface Acoustic Wave (SAW) devices for the selective detection of $\mathrm{CO}$ and $\mathrm{CH}_{2} \mathrm{O}$.

\section{A. Materials and Methods}

1) SAW devices: SAW delay lines based on Love waves, shown in Figure 1, are used to probe mass, density or elastic properties of sensitive materials deposited as a thin layer on its surface. In this context, together with the manufacturing of the SAW device, we have developed sensitive layers capable of efficiently and selectively trap a target gas. These devices consist in two-port delay lines built on (AT, Z) cut of quartz. The Love wave is generated and detected using interdigited transducers (IDTs) composed of 50 pairs of electrodes made 


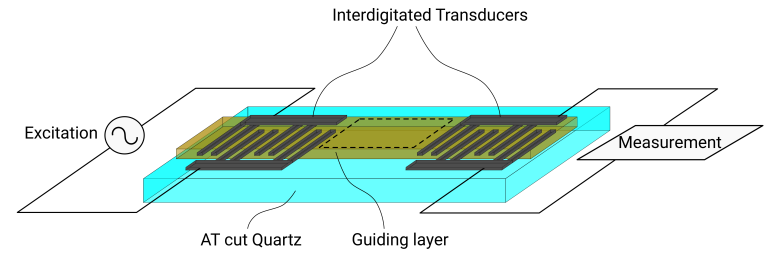

Fig. 1. Structure of the SAW device used for the manufacturing of the gas sensors. These sensors are based on a delay line configuration exhibiting a free propagation path (dotted line area) where the sensitive material is deposited.

of $200 \mathrm{~nm}$ thick evaporated aluminum. The grating period is $10 \mu \mathrm{m}$, i.e. a wavelength close to $40 \mu \mathrm{m}$ yielding a frequency operation in the vicinity of $125 \mathrm{MHz}$ as the wave velocity approaches $5000 \mathrm{~m} \cdot \mathrm{s}^{-1}$. A $1 \mu \mathrm{m}$ thick silica guiding layer is deposited onto the IDTs providing a propagation path which permit the guidance of the acoustic wave.

The electrical response of the device can be determined using a network analyzer. However, a dedicated and integrated electronics has been implemented and delivers information similar to those from a classical network analyzer. This system includes two separated phase measurement schemes: a rough characterization stage using the $A D 8302$ phase and magnitude detector, and a high sensitivity phase measurement stage using dedicated phase detectors $A D 9954$ with variable gain and low noise operational amplifiers as presented in another work [5].

2) Formaldehyde sensitive material: For the production of the $\mathrm{CH}_{2} \mathrm{O}$ sensor, two different sensitive materials were tested; a first layer referred as L1 displays a specific nano-porosity allowing the trapping of small molecules such as $\mathrm{CH}_{2} \mathrm{O}$. A second sensitive layer referred as L2 displays functional groups aimed at improving the molecular interaction with $\mathrm{CH}_{2} \mathrm{O}$. Both materials were produced via the sol-gel process and were deposited as thin films on the SAW device by spin-coating. The properties of these recognition layers is not detailed here for confidentiality reasons.

3) Carbon nonoxide sensitive material: For the functionalization of the $\mathrm{CO}$ sensors, we took advantage of the great capabilities of cobalt corroles to trap this molecule [6], with a great selectivity toward $\mathrm{O}_{2}$, the main interferent in $\mathrm{CO}$ measurement [7]. Because of the structure of the corroles, small molecules such as $\mathrm{N}_{2}, \mathrm{O}_{2}$ and $\mathrm{CO}$ can be trapped within by mean of weak interactions. In the particular case of $\mathrm{CO}$, stronger chemical interactions are involved reaching high selectivity for this gas. The use of a variety of cobalt corroles including new structures of corroles complexes represents an innovative aspect of this work.

\section{B. Results}

Modifications of the physical properties of the sensitive layer consecutive to gas adsorption lead to a shift of the synchronous frequency of the delay line. Since the phase is linear with the frequency in the vicinity of the synchronous frequency for such a device, the frequency shift can be revealed by a phase shift measurement at constant frequency. The characterization of the adsorption of the target gas onto

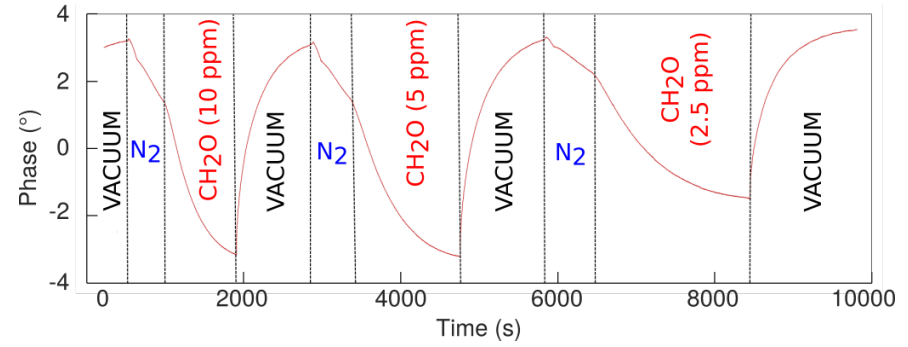

Fig. 2. Measurements of $\mathrm{CH}_{2} \mathrm{O}$ concentrations with SAW devices functionalized with sensitive layer L1.

the surface is then achieved by calculating the slope of the phase at the beginning of its decrease. This approach allows to measure concentrations of gas within a few tens of seconds.

1) Formaldehyde Measurements: As shown on Figure 2, with the first layer L1 displaying a specific porosity adapted to the trapping of $\mathrm{CH}_{2} \mathrm{O}$, a drift of the signal in the presence of $\mathrm{N}_{2}$ used as a carrier gas is observed indicating that $\mathrm{N}_{2}$ molecules are also adsorbed in the nano-porous layer. This lack of selectivity induces a weak sensitivity of the sensor to $\mathrm{CH}_{2} \mathrm{O}$. As a matter of fact, it enables the detection of $\mathrm{CH}_{2} \mathrm{O}$ only at concentrations superior or equal to $2.5 \mathrm{ppm}$ which do not fit with the required WHO detection threshold.

Based on these results, the second functionalized sensitive layer $\mathrm{L} 2$ have been used to enhance $\mathrm{CH}_{2} \mathrm{O}$ adsorption at the expense of $\mathrm{N}_{2}$ adsorption. One can see in Figure 3(a) that with L2, the drift caused by the exposure to $\mathrm{N}_{2}$ is substantially reduced and the sensitivity is strongly improved, allowing the detection of $\mathrm{CH}_{2} \mathrm{O}$ at concentrations as low as $80 \mathrm{ppb}$ with a sensitivity of $2.6 \cdot 10^{-3}{ }^{\circ} . \mathrm{s}^{-1} \cdot \mathrm{ppm}^{-1}$.

Nevertheless, figure 4(a) shows that the sensor suffers from a lack of selectivity toward humidity. Several characterizations of the sensors response under different relative humidity were carried out in order to determine the influence of this parameter on the sensors sensitivity. Figure 4(b) shows that under 10 $\% \mathrm{RH}$ conditions, the sensitivity is divided by 7.5 in relation to dry conditions. Furthermore, the limit of detection increases to $100 \mathrm{ppb}$ and $500 \mathrm{ppb}$ respectively under $10 \% \mathrm{RH}$ and $20 \% \mathrm{RH}$ conditions while $80 \mathrm{ppb}$ can be reached in dry conditions. The effect of adding a hydrophobic fluorinated chain in the formulation of the sensitive material is currently studied. We expect tat the improvement of this formulation will minimize the sensitivity to humidity and hence improve the selectivity of the sensor.

2) Carbon Monoxide Measurements: SAW delay line covered with new structures of corroles have been exposed to $\mathrm{CO}$ at low concentration. Figure 5(a) represents the sensor response to $\mathrm{CO}$ diluted in $\mathrm{N}_{2}$ in the $10 \mathrm{ppm}$ to $200 \mathrm{ppb}$ range. This sensor has shown a great sensitivity to $\mathrm{CO}$ allowing the detection of concentration as low as $200 \mathrm{ppb}$. One can see a drift of the signal following the detection. This behavior is attributed to temperature changes when shifting from the carrier gas to the target gas. In order to address a response to that issue, a second delay line used as a temperature 


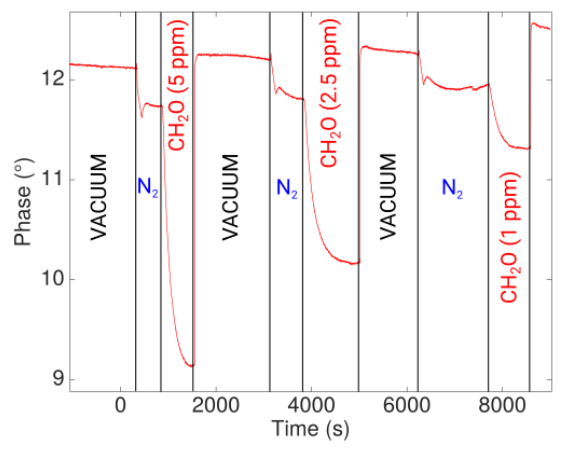

(a)

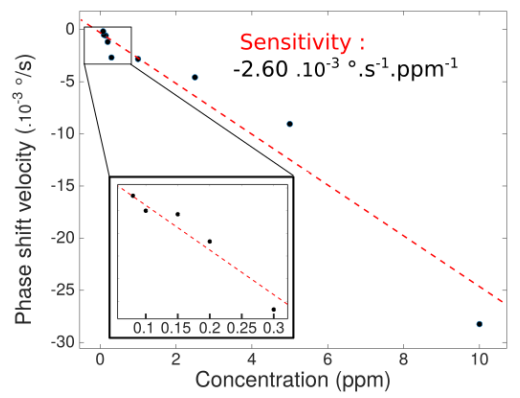

(b)

Fig. 3. (a) Measurements of $\mathrm{CH}_{2} \mathrm{O}$ concentration with $\mathrm{SAW}$ devices functionalized with sensitive layer L2; (b) The correlation between the phase shift velocity during the exposure and the concentration of $\mathrm{CH}_{2} \mathrm{O}$

reference is currently under development. Figure 5(b) shows that despite of the temperature-related measurement problems, the signals observed are correlated to the $\mathrm{CO}$ concentration with a sensitivity of $1.32 \cdot 10^{-3}{ }^{\circ} . \mathrm{s}^{-1} \cdot \mathrm{ppm}^{-1}$.

\section{CONCLUSION}

In this study, we have demonstrated a linear correlation between the phase velocity shifts of the Love wave and the concnetration of the target gases. The experiments were repeated several times to validate the results under various concentrations. We have shown that the use of Love wave devices functionalized with sensitive materials such as corrole complexes or nano-porous layers enables gas detection at concentrations as low as a few tens of ppb for $\mathrm{CH}_{2} \mathrm{O}$ and a few hundreds of ppb in the case of CO. Besides the cross-sensitivity to humidity, these results pave the way to investigating other gas detection with specific functionalized acoustic waves devices.

\section{ACKNOWLEDGMENT}

The authors are grateful to the French National Research Agency (ANR CO3SENS project) and to bpi-France (SMARTY project $\mathrm{N}^{\circ} 165022$ ) for their financial supports. V. Quesneau also thanks the Region Bourgogne for providing his $\mathrm{PhD}$ grant. This work was also partly supported by the French RENATECH network and its FEMTO-ST technological facility.

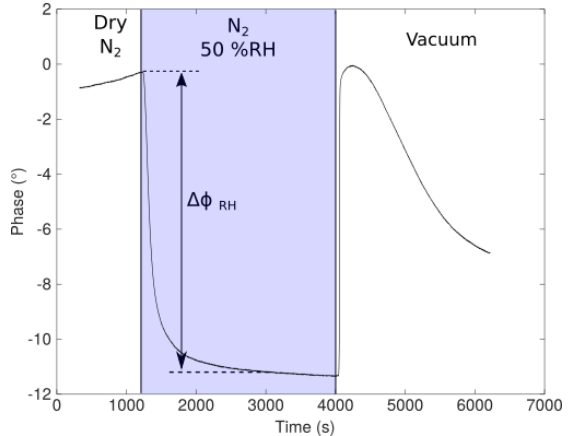

(a)

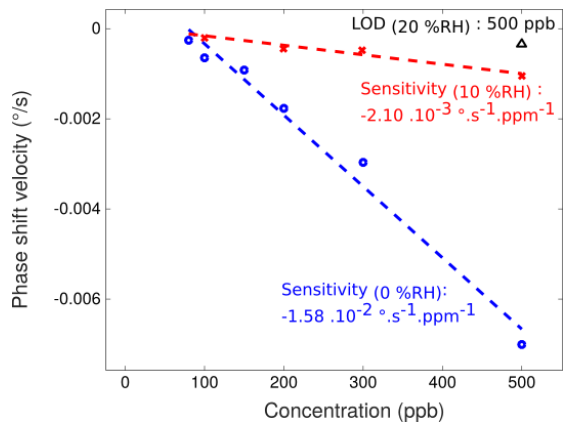

(b)

Fig. 4. (a) Measurements of $\mathrm{CH}_{2} \mathrm{O}$ concentration with SAW devices functionalized with sensitive layer L2; (b) The correlation between the phase shift velocity during the exposure and the concentration of $\mathrm{CH}_{2} \mathrm{O}$

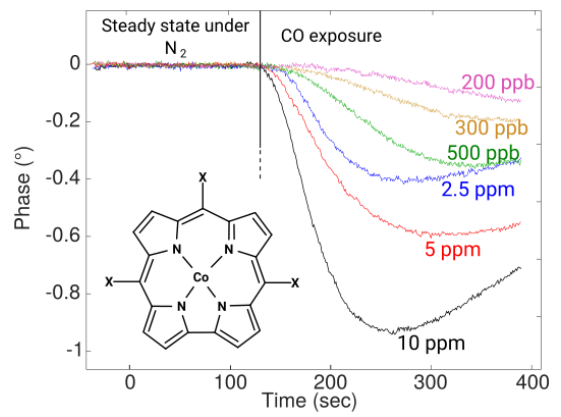

(a)

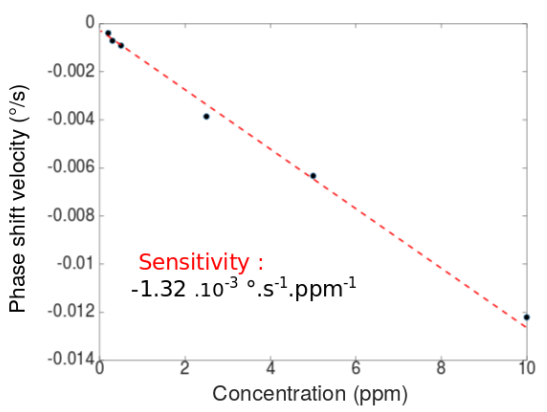

(b)

Fig. 5. (a) Phase signals of a functionalized SAW device to carbon monoxide in the $10 \mathrm{ppm}$ to $200 \mathrm{ppb}$ range; (b) Correlation between the phase shift velocity during the exposure and the concentration of carbon monoxide 


\section{REFERENCES}

[1] W. Kim, N. Terada, T. Nomura, R. Takahashi, S. Lee, J. Park, and A. Konno, "Effect of formaldehyde on the expression of adhesion molecules in nasal microvascular endothelial cells: the role of formaldehyde in the pathogenesis of sick building syndrome," Clinical \& Experimental Allergy, vol. 32, no. 2, pp. 287-295, 2002.

[2] J. A. Raub, M. Mathieu-Nolf, N. B. Hampson, and S. R. Thom, "Carbon monoxide poisoning a public health perspective," Toxicology, vol. 145, no. 1 , pp. $1-14,2000$

[3] World Health Organization (WHO) et al., "WHO guidelines for indoor air quality: selected pollutants," no. 2010, 2010.

[4] A. Verrier, C. Ménard, P. Ardwison, C. Perrey, and J. Thiolet, "Caractéristiques socio-économiques des ménages accidentellement intoxiqués par le monoxyde de carbone (CO)," Bull Epidémiol Hebd, pp. 2-3, 2016.

[5] D. Rabus, J.-M. Friedt, S. Ballandras, G. Martin, E. Carry, and V. Blondeau-Patissier, "High-sensitivity open-loop electronics for gravimetric acoustic-wave-based sensors," IEEE transactions on ultrasonics, ferroelectrics, and frequency control, vol. 60, no. 6, pp. 1219-1226, 2013.

[6] K. M. Kadish, Z. Ou, J. Shao, C. P. Gros, J.-M. Barbe, F. Jérôme, F. Bolze, F. Burdet, and R. Guilard, "Alkyl and aryl substituted corroles. 3. reactions of cofacial cobalt biscorroles and porphyrin-corroles with pyridine and carbon monoxide," Inorganic chemistry, vol. 41, no. 15, pp. 3990-4005, 2002.

[7] J.-M. Barbe, G. Canard, S. Brandès, F. Jérôme, G. Dubois, and R. Guilard, "Metallocorroles as sensing components for gas sensors: remarkable affinity and selectivity of cobalt (III) corroles for $\mathrm{CO}$ vs. $\mathrm{O}_{2}$ and $\mathrm{N}_{2}$," Dalton Transactions, no. 8, pp. 1208-1214, 2004 